\title{
Do girls and boys perceive themselves as equally engaged in school? The results of an international study from 12 countries
}

Shui-fong Lam ${ }^{\mathrm{a}, *}$, Shane Jimerson ${ }^{\mathrm{b}}$, Eve Kikas ${ }^{\mathrm{c}, \mathrm{d}}$, Carmel Cefai ${ }^{\mathrm{e}}$, Feliciano H. Veiga ${ }^{f}$, Brett Nelson ${ }^{g}$, Chryse Hatzichristou ${ }^{\mathrm{h}}$, Fotini Polychroni ${ }^{\mathrm{h}}$, Julie Basnett ${ }^{\mathrm{i}}$, Robert Duck ${ }^{\mathrm{j}}$, Peter Farrell ${ }^{\mathrm{k}}$, Yi Liu ${ }^{\mathrm{l}}$, Valeria Negovan ${ }^{\mathrm{m}}$, Hyeonsook Shin ${ }^{\mathrm{n}}$, Elena Stanculescu ${ }^{\mathrm{m}}$, Bernard P.H. Wong ${ }^{\mathrm{a}}$, Hongfei Yang ${ }^{\mathrm{O}}$, Josef Zollneritsch ${ }^{\mathrm{p}}$

a University of Hong Kong, China

${ }^{\mathrm{b}}$ University of California - Santa Barbara, USA

${ }^{\mathrm{c}}$ University of Tartu, Estonia

d University of Tallinn, Estonia

e University of Malta, Malta

${ }^{\mathrm{f}}$ University of Lisbon, Portugal

g California State University - San Bernardino, USA

${ }^{\mathrm{h}}$ University of Athens, Greece

i St Helens Metropolitan Borough Council, UK

${ }^{\mathrm{j}}$ Laurentian University, Canada

${ }^{\mathrm{k}}$ University of Manchester, UK

${ }^{1}$ Yunnan Health Education Institute, China

${ }^{\mathrm{m}}$ University of Bucharest, Romania

\footnotetext{
is Shui-fong Lam, Department of Psychology, University of Hong Kong, China; Shane Jimerson, Department of Counseling, Clinical, and School Psychology, University of California - Santa Barbara, United States; Eve Kikas, Institute of Education, University of Tartu and Institute of Psychology, University of Tallinn, Estonia; Carmel Cefai, Department of Psychology, University of Malta, Malta; Feliciano H. Veiga, Institute of Education, University of Lisbon, Portugal; Brett Nelson, Department of Educational Psychology and Counseling, California State University San Bernardino, United States; Chryse Hatzichristou, Department of Psychology, University of Athens, Greece; Fotini Polychroni, Department of Psychology, University of Athens, Greece; Julie Basnett, St Helens Metropolitan Borough Council, United Kingdom; Robert Duck, Department of Psychology, Barrie University Partnership Centre, Laurentian University, Canada; Peter Farrell, School of Education, University of Manchester, United Kingdom; Yi Liu, Yunnan Health Education Institute, China; Valeria Negovan, Department of Psychology, University of Bucharest, Romania; Hyeonsook Shin, Department of Education, Chonnam National University, South Korea; Elena Stanculescu, Department of Teacher Training, University of Bucharest, Romania, Bernard P. H. Wong, Department of Psychology, University of Hong Kong, China; Hongfei Yang, Department of Psychology and Behavioral Sciences, Zhejiang University, China; Josef Zollneritsch, Styria Local Ministry of Education, Austria. The first eight authors appear in the order of their contributions whereas the rest are listed in alphabetical order according to their surnames. The data of this article were part of the data collected in a multicountry project initiated by the International School Psychology Association (Lam et al., 2009). The Hong Kong subproject was supported by the Quality Education Fund of the Education Bureau in Hong Kong whereas the Portuguese subproject was supported by the Portuguese Foundation for Science and Technology and by the Institute of Education of the University of Lisbon. The authors wish to thank the following colleagues for their assistance to this research: Ana Almeida, Terry Au, Sara Bahía, Suzana Caldeira, Carolina Carvalho, Isabel Festas, Isabel Janeiro, Madalena Melo, João Nogueira.

* Corresponding author at: Department of Psychology, University of Hong Kong, Pokfulam Road, Hong Kong, China. Tel.: + 852 2859 2388; fax: + 85228583518.

E-mail address: lamsf@hku.hk (S.-f. Lam).

ACTION EDITOR: Michelle Demaray.
}

0022-4405/\$ - see front matter @ 2011 Society for the Study of School Psychology. Published by Elsevier Ltd. All rights reserved. doi:10.1016/j.jsp.2011.07.004 
${ }^{\mathrm{n}}$ Chonnam National University, South Korea

${ }^{\circ}$ Zhejiang University, China

p Styria Local Ministry of Education, Austria

\section{A R T I C L E I N F O}

\section{Article history:}

Received 4 February 2010

Received in revised form 31 July 2011

Accepted 31 July 2011

\section{Keywords:}

Academic performance

Gender differences

Student engagement

Teacher support

Parent support

Peer support

\begin{abstract}
A B S T R A C T
This study examined gender differences in student engagement and academic performance in school. Participants included 3420 students (7th, 8th, and 9th graders) from Austria, Canada, China, Cyprus, Estonia, Greece, Malta, Portugal, Romania, South Korea, the United Kingdom, and the United States. The results indicated that, compared to boys, girls reported higher levels of engagement in school and were rated higher by their teachers in academic performance. Student engagement accounted for gender differences in academic performance, but gender did not moderate the associations among student engagement, academic performance, or contextual supports. Analysis of multiple-group structural equation modeling revealed that perceptions of teacher support and parent support, but not peer support, were related indirectly to academic performance through student engagement. This partial mediation model was invariant across gender. The findings from this study enhance the understanding about the contextual and personal factors associated with girls' and boys' academic performance around the world.

(c) 2011 Society for the Study of School Psychology. Published by Elsevier Ltd. All rights reserved.
\end{abstract}

\section{Introduction}

The phenomenon that girls obtain better school grades than boys has been reported around the world in the last two decades. In many countries, it is true throughout primary, secondary school, and even in college years (e.g., Epstein, Elwood, Jey, \& Maw, 1998; Mau \& Lynn, 2001; Perkins, Kleiner, Roey, \& Brown, 2004; Pomerantz, Alterman, \& Saxon, 2002; Van Houtte, 2004; Willingham \& Cole, 1997; Wong, Lam, \& Ho, 2002). Although women are still underrepresented in science and mathematics (Ceci, Williams, \& Barnett, 2009), they compose nearly $60 \%$ of the university student populations in many developed countries (Johnson, 2008). It is important to understand the factors underlying this gender gap in academic achievement. Several researchers (e.g., Freudenthaler, Spinath, \& Neubauer, 2008; Hicks, Johnson, Iacono, \& McGue, 2008; Johnson, 2008; Ruban \& McCoach, 2005) have argued that gender differences in school performance lie in personality and motivation factors instead of cognitive factors. In the realms of personality and motivation, student engagement is an important variable to account for gender differences in school achievement. This article explores the association between student engagement and academic achievement for boys and girls in 12 countries with diverse cultural and ethnic backgrounds.

\subsection{Student engagement in school}

In recent years, student engagement in school has become an increasingly important concept for researchers in education (Fredricks, Blumenfeld, \& Paris, 2004). Many studies have indicated that student engagement is predictive of student academic performance (Connell, Spencer, \& Aber, 1994; DiPerna, Volpe, \& Elliott, 2005; Skinner \& Belmont, 1993; Wu, Hughes, \& Kwok, 2010). These findings are consistent with Walberg's (1981) theory of educational productivity that psychological characteristics of students and their immediate environment influence student outcomes. Student engagement is an example of a psychological characteristic that is susceptible to contextual influences and predictive of academic performance.

Although there is a consensus that student engagement is important to student academic performance, there is little consensus about its conceptualization and measurement. Most researchers agree that it is a metaconstruct encompassing multiple dimensions of involvement in school or commitment in learning 
(Fredricks et al., 2004; Jimerson, Campos, \& Greif, 2003; Sinclair, Christenson, Lehr, \& Anderson, 2003). However, the number and nature of dimensions within this metaconstruct remain unclear. Some researchers use a three-part typology and conceptualize it as comprising affective, behavioral, and cognitive dimensions (Fredricks et al., 2004; Jimerson et al., 2003; Lam et al., 2009), whereas some researchers use a four-part typology and add an academic dimension as well (Appleton, Christenson, Kim, \& Reschly, 2006). Some researchers include antecedents of student engagement, such as teacher support and peer relationships, in the measurement of student engagement (e.g., Appleton et al., 2006), whereas others include outcomes, such as grades and discipline (e.g., Archambault, Janosz, Fallu, \& Pagani, 2009).

Including multiple dimensions in a metaconstruct provides researchers with a broader perspective for the understanding of student engagement in school. However, clarifications must be made to the number and nature of its dimensions. Otherwise, a comprehensive but elusive metaconstruct may cause more confusion than understanding. Three concerns regarding the conceptualization and measurement of this metaconstruct need to be addressed. First, a distinction should be made between indicators and facilitators of student engagement. Indicators refer to the features that define student engagement, whereas facilitators are contextual factors that influence student engagement (Sinclair et al., 2003). Indicators are the characteristics that belong within the construct of student engagement itself (e.g., student's effort and enthusiasm in school work). Facilitators are the causal factors residing outside the construct but will influence engagement (e.g., teacher support). Skinner, Furrer, Marchand, and Kindermann (2008) emphasized that facilitators should not be defined as part of student engagement itself. Otherwise, researchers cannot explore how contextual factors, such as teacher support, influence engagement. Second, a distinction should be made between indicators and outcomes of student engagement. Outcomes such as grades and conduct should not be defined as part of student engagement itself, as this definition would make it difficult to explore the consequences of student engagement. Third, the dimensions of student engagement should not overlap, although they are not isolated processes and should be interrelated dynamically within individual students. Otherwise, the justification for the proposed dimensions would be in question.

With reference to the above concerns, the present study adopts a three-part typology and conceptualizes student engagement as a metaconstruct that comprises affective, behavioral, and cognitive dimensions. They are the most critical dimensions of student involvement in school (Fredricks et al., 2004; Jimerson et al., 2003). Affective engagement refers to students' feelings about learning (Connell \& Wellborn, 1991; Skinner \& Belmont, 1993) and the school they attend (Finn, 1989; Voelkl, 1997). The feelings about learning activities are reflections of intrinsic motivation, whereas the feelings about the school are a manifestation of attachment to school. Students with high affective engagement enjoy learning and love going to school. Behavioral engagement refers to student participation in learning (Birch \& Ladd, 1997; Skinner \& Belmont, 1993) and extra-curricular activities in school (Finn, Pannozzo, \& Voelk1, 1995). Students with high behavioral engagement are diligent in learning activities and active in extracurricular activities. Cognitive engagement refers to the amount and types of cognitive strategies that students employ (Walker, Greene, \& Mansell, 2006). Students may employ deep or shallow processing strategies. Deep processing is associated with cognitive elaboration of the to-be-learned material, whereas shallow processing involves rote memorization, basic rehearsal, and other types of superficial engagement with the new material. Students who engage in deep cognitive processing have better understanding and retention of meaningful learning materials.

In this three-part typology, the three dimensions of student engagement have clear and distinctive features that do not overlap with one another. The components in each of the dimensions are wellestablished constructs in the literature. They have been addressed separately by robust bodies of work. For example, enjoyment in learning, a component of affective engagement, is often referred to as intrinsic motivation, a well-researched construct in the field of motivation (e.g., Ryan \& Deci, 2000). In other words, intrinsic motivation is included in the metaconstruct of student engagement. To build a metaconstruct on well-defined and well-researched constructs enables researchers to tap into the existing body of knowledge and examine their additive and interactive effects simultaneously and dynamically.

\subsection{Gender considerations}

Few studies have investigated gender differences in student engagement. However, there have been studies on gender differences in the many components of student engagement (e.g., intrinsic motivation 
and persistence in school work) (Barber, 1996; Darom \& Rich, 1988; Warrington, Younger, \& Williams, 2000). As intrinsic motivation and persistence constitute the first two dimensions of student engagement, these findings will have implications regarding gender differences in student engagement. It has been reported that boys are less motivated than girls and spend less time doing homework and that boys have lower expectations of themselves and are less enthusiastic about continuing their studies (Barber, 1996; Cox, 2000; Darom \& Rich, 1988; Hatzichristou \& Hopf, 1996; Warrington et al., 2000). As for the cognitive dimension of student engagement, there is also evidence showing that girls are more likely than boys to plan, monitor, and regulate their cognitions and study activities (Ablard \& Lipschultz, 1998; KenneyBenson, Pomerantz, Ryan, \& Patrick, 2006; Patrick, Ryan, \& Pintrich, 1999; Zimmerman \& Martinez-Pons, 1990). On the basis of the extant evidence, one may speculate that the gender differences in student engagement might influence gender differences in academic performance.

In addition to different levels of student engagement, the different associations between student engagement and academic performance across girls and boys may also be held responsible for the gender differences in academic performance. In a study with 1353 Austrian students, Freudenthaler et al. (2008) found that school-related intrinsic motivation was more important to school achievement for boys than for girls. They argued that their results may indicate that liking what they are doing is particularly important to boys. Girls, on the other hand, can engage in tasks that they might not like. Because school work may not always be interesting or enjoyable, this difference constitutes an advantage to girls. They exert effort and remain engaged in tasks even when the tasks seem to be boring. However, the findings of Freudenthaler et al. (2008) were not conclusive, as other studies reported conflicting evidence. For instance, Steinmayr and Spinath (2008) did not find any gender difference in the relations between motivation and school achievement. Similarly, Ruban and McCoach (2005) found no gender differences in the impact of selfregulatory and motivation factors on college academic achievement. They did a multiple-group analysis and found that these predictors function similarly across the two genders. In view of these contradictory findings, further investigation is warranted to explore the association between student engagement and academic performance across girls and boys.

\subsection{Contextual antecedents}

Investigation of the gender gap in academic achievement should also include contextual antecedents of student engagement. Interventions to promote student engagement must take these contextual antecedents into consideration. Like any personality factors, student engagement develops in an intricate web of mutually influencing contexts. According to the socio-ecological theory of Bronfenbrenner (1977), human development occurs in a nested arrangement of systems, each contained within the next. The most immediate systems in which a human organism develops are the microsystems (e.g., school, family, and workplace). The dynamics and relationships in these microsystems have a significant impact on human development. To learn about how student engagement develops, it is important to explore its antecedents in school and family. In particular, important agents of socialization should be considered, namely teachers, parents, and peers.

It is very likely that relationships with teachers, parents, and peers influence student engagement in school. According to self-determination theory (Ryan \& Deci, 2000), relatedness - the connection and sense of belonging to others - is fundamental to the enhancement of motivation. As discussed earlier, motivation is a component of student engagement, and relatedness is thus fundamental to the enhancement of student engagement. The need for connectedness and belonging is universal across cultures, and the fulfillment of this need provides students with the required emotional security for active engagement in school. A cursory reading of the literature shows that support from teachers, parents, and peers facilitates student engagement in school (e.g., Chen, 2005; Ladd, Kochenderfer, \& Coleman, 1997; Skinner \& Belmont, 1993; Steinberg, Lamborn, Dornbusch, \& Darling, 1992; Wentzel, 1998).

Past research has shown that positive student-teacher interactions contribute to students' motivation and academic achievement. Children and adolescents who report a higher sense of relatedness to teachers show greater emotional and behavioral engagement (Connell \& Wellborn, 1991; Eccles et al., 1993; Furrer \& Skinner, 2003; Gest, Welsh, \& Domitrovich, 2005; Murray \& Greenberg, 2001; Wentzel, 1998). Hence, it may be expected that the social and emotional support (i.e., care and concern) from teachers would be conducive to the development of student engagement. 
Although teachers are important socialization agents in the school system, parents are the equivalent in the family system. It is well documented that parenting styles (e.g., Steinberg et al., 1992) and parental involvement (e.g., Waanders, Mendez, \& Downer, 2007) contribute to a student's academic performance. Thus, it may be expected that parent support (i.e., expectation, encouragement, assistance, and monitoring) would play an important role in student engagement in school.

Schools and families are two microsystems in which students are embedded. However, peers are another pertinent microsystem. This statement is particularly true during adolescence when primary socialization responsibility shifts from the family to peers and the school (Harris, 1998). Research on school bullying and victimization has revealed that students with larger circles of friends, higher levels of peer acceptance, and lower levels of peer victimization tend to like school more (Ladd et al., 1997). Peer support is a strong predictor of student achievement (Cowie \& Fernández, 2006; Rosenfeld, Richman, \& Bowen, 2000). In view of the importance of peer influences during adolescence, it is important to examine how social emotional support from peers is associated with student engagement and academic performance.

In the past, many studies have examined the impact of teacher, parent, and peer support on student adjustment in school (e.g., Furrer \& Skinner, 2003; Hoover-Dempsey \& Sandler, 1995; Ladd et al., 1997). However, few studies have examined all the three supports in a single study. Chen (2005) is a rare exception in this respect. Examining data from 270 Hong Kong adolescents, Chen found that the effects of these three contextual factors on academic achievement were mediated partially by student engagement. That is, student engagement was the mediator in the relations between the three contextual factors and academic achievement. However, gender differences were not examined in Chen (2005). To increase educators' understanding of the gender gap in academic achievement, it is important to explore whether this partial mediation model could be replicated for both genders across countries.

\subsection{The present study}

This study investigated gender differences in student engagement in school and examined how student engagement in school was associated with contextual supports and academic achievement across the two genders. There were four key objectives of the study. The first objective was to investigate, with an international sample, whether girls and boys have different levels of engagement in school and different perceptions of teacher, parent, and peer support. The second objective was to investigate whether gender differences in school engagement account for the gender gap in academic achievement. The third objective was to investigate gender differences in the relations among contextual supports, student engagement and academic performance. The fourth objective was to investigate whether teacher, parent, and peer support have similar or different indirect effects on student engagement for boys and girls.

The data in the present study were part of the data collected in a multicountry project initiated by the International School Psychology Association (Lam et al., 2009). The purpose of this international collaborative project was to investigate both the personal and contextual antecedents of student engagement in schools across different countries. The present study stems from this large-scale project that involved many variables and themes of investigation. In this article, the focus is the four objectives that are related to the investigation of gender differences in student engagement and academic performance. It should be noted that cultural differences were not the focus of this study. Previous data analyses (Lam et al., 2009) have revealed that how student engagement was related to contextual factors did not vary between countries according to an indicator (Hofstede, 2009) that distinguishes individualistic from collectivistic cultures. Therefore, cultural differences have not been pursued in this article.

\section{Method}

\subsection{Participants}

The participants were 3420 7th-, 8th-, and 9th-grade students from 12 countries (Austria, Canada, China, Cyprus, Estonia, Greece, Malta, Portugal, Romania, South Korea, the United Kingdom, and the United States). Following a sampling plan, data were collected from 300 students in each country (i.e., 100 7th graders, 100 8th graders, and 100 9th graders). For the purpose of cross-country comparison, research partners from each country recruited students from urban schools with typical students. Schools in rural 
areas and schools catering to high-achieving students or special schools were not included in the sample. In some countries, research partners from more than one city joined the project. Thus, stratified random sampling from the data of all the cities involved produced a sample of 300 students for each of these countries. For example, the research teams from three cities in China each collected 100 7th graders, 100 8th graders, and 100 9th graders. Thus, the final Chinese sample was composed of 300 students selected randomly and proportionally from these 900 students (gathered across the three cities) according to city, grade, and gender. In total, 48 schools from 25 cities in 12 countries were involved in the present study. Because 29 participants did not report their genders, the sample consisted of 1725 girls and 1666 boys. The mean age of the students was 13.82 with a range of 11 to 17 and a standard deviation of 1.15. The percentages of 7 th graders, 8th graders, and 9th graders were $34.8 \%, 30.9 \%$, and $34.3 \%$, respectively. For the breakdown of the demographic information in each of the 12 countries, please see Table 1.

\subsection{Measures}

The students completed a questionnaire measuring teacher support, parent support, peer support, and student engagement. Meanwhile their teachers completed a rating form reporting their academic performance.

Table 1

The demographics of the samples in the 12 countries.

\begin{tabular}{|c|c|c|c|c|c|}
\hline Country & Cities & Schools & $N$ & Grade & Age \\
\hline \multirow[t]{3}{*}{ Austria } & Graz & 1 & 154 & 7th: $35.7 \%$ & 13.70 \\
\hline & & & G: $59.7 \%$ & 8th: $31.2 \%$ & $(1.04)$ \\
\hline & & & B: $39.6 \%$ & 9th: $33.1 \%$ & \\
\hline \multirow[t]{3}{*}{ Canada } & Barrie and Orillia & 9 & 300 & 7th: $33.3 \%$ & 13.42 \\
\hline & & & G: $49.7 \%$ & 8th: $33.3 \%$ & $(1.01)$ \\
\hline & & & B: $50.3 \%$ & 9th: $33.3 \%$ & \\
\hline \multirow[t]{3}{*}{ China } & Hangzhou, Hong Kong, and Kunming & 3 & 300 & 7th: $33.3 \%$ & 14.13 \\
\hline & & & G: $50.7 \%$ & 8th: $33.3 \%$ & $(1.23)$ \\
\hline & & & B: $49.3 \%$ & 9th: $33.3 \%$ & \\
\hline \multirow[t]{3}{*}{ Cyprus } & Larnaka & 4 & 300 & 7th: $33.3 \%$ & 13.72 \\
\hline & & & G: $54.4 \%$ & 8th: $33.3 \%$ & $(0.99)$ \\
\hline & & & B: $45.6 \%$ & 9th: $33.3 \%$ & \\
\hline \multirow[t]{3}{*}{ Estonia } & Tallinn, Saue, Keila, and Rapla & 4 & 303 & 7th: $20.9 \%$ & 14.73 \\
\hline & & & G: $45.9 \%$ & 8th: $38.7 \%$ & $(0.89)$ \\
\hline & & & B: $54.1 \%$ & 9th: $40.4 \%$ & \\
\hline \multirow[t]{3}{*}{ Greece } & Athens & 6 & 300 & 7th: $33.3 \%$ & 13.56 \\
\hline & & & G: $48.0 \%$ & 8th: $33.3 \%$ & $(1.01)$ \\
\hline & & & B: $52.0 \%$ & 9th: $33.3 \%$ & \\
\hline \multirow[t]{3}{*}{ Malta } & Hamrun and St. Lucija & 2 & 280 & 7th: $29.3 \%$ & 12.86 \\
\hline & & & G: $50 \%$ & 8th: $30.0 \%$ & $(1.10)$ \\
\hline & & & B. $50 \%$ & 9th: $40.7 \%$ & \\
\hline \multirow[t]{3}{*}{ Portugal } & Lisbon, Ponta Delgada, Évora, Aveiro, and Braga & 5 & 260 & 7th: $38.4 \%$ & 13.78 \\
\hline & & & G: $57.9 \%$ & 8th: $30.8 \%$ & $(1.17)$ \\
\hline & & & B: $42.1 \%$ & 9th: $30.8 \%$ & \\
\hline \multirow[t]{3}{*}{ Romania } & Bucharest & 4 & 300 & 7th: $33.3 \%$ & 14.38 \\
\hline & & & G: $50 \%$ & 8th: $33.3 \%$ & $(0.95)$ \\
\hline & & & B : $50 \%$ & 9th: $33.3 \%$ & \\
\hline \multirow[t]{3}{*}{ South Korea } & Seoul and Gwangju & 5 & 300 & 7th: $37.0 \%$ & 13.55 \\
\hline & & & G: $51.7 \%$ & 8th: $34.3 \%$ & $(0.92)$ \\
\hline & & & $\mathrm{B}: 48.3 \%$ & 9th: $28.7 \%$ & \\
\hline \multirow[t]{3}{*}{ UK } & St. Helens & 1 & 323 & 7th: $39.0 \%$ & 13.00 \\
\hline & & & G: $50.8 \%$ & 8th: $31.6 \%$ & $(1.00)$ \\
\hline & & & B: $49.2 \%$ & 9th: $29.4 \%$ & \\
\hline \multirow[t]{3}{*}{ US } & Santa-Barbara and Riverside & 4 & 296 & 7th: $51.3 \%$ & 14.31 \\
\hline & & & G: $46.5 \%$ & 8th: $7.0 \%$ & $(0.93)$ \\
\hline & & & B: $53.5 \%$ & 9th: $41.7 \%$ & \\
\hline \multirow[t]{3}{*}{ Total } & 25 & 48 & 3420 & 7th: $34.8 \%$ & 13.82 \\
\hline & & & G: $50.9 \%$ & 8th: $30.9 \%$ & $(1.15)$ \\
\hline & & & B: $49.1 \%$ & 9th: $34.3 \%$ & \\
\hline
\end{tabular}

Note. G is girl, and B is boy. Numbers in parentheses are standard deviations. 


\subsubsection{Teacher support}

Student perception of teacher support was measured by three items adapted from the Caring Adult Relationships in School Scale of the California Healthy Kids Survey (WestEd, 2000). These three items were (a) "At my school, there is a teacher who cares about me," (b) "At my school, there is a teacher who is kind to me," and (c) "At my school, there is a teacher who listens to me when I have something to say." Students were asked to indicate how much they agreed to these three statements on a 5-point Likert scale with 1 for strongly disagree and 5 for strongly agree. The average score from the three items was used to indicate the levels of teacher support perceived by the students. High scores indicated a perception of high teacher support. The coefficient $\alpha$ of the three item-scores was .79. The teacher support questionnaire was administered again to the Hong Kong subsample $(n=100) 6$ months later. The test-retest reliability was $.54(p<.001)$.

\subsubsection{Parent support}

Student perception of parent support was measured by eight items adapted from the components of home support for learning in the Functional Assessment of Academic Behavior (Ysseldyke \& Christenson, 2002). These items described parent involvement in their child's learning, such as asking their children about school, monitoring their academic progress, and discussing schoolwork with them at home. The students indicated the frequency of their parent support as stated in these items on a 5-point Likert scale with 1 for never and 5 for always. The average of scores from the eight items was used to indicate the levels of parent support perceived by the students. High scores indicated perceptions of high parent support. The coefficient $\alpha$ of the eight item-scores was .85. The test-retest reliability of this measure for the Hong Kong subsample $(n=100)$ was .66 $(p<.001)$.

\subsubsection{Peer support}

Student perception of teacher support was measured by three items adapted from the Caring Peer Relationships in School Scale of the California Healthy Kids Survey (WestEd, 2000). These three items were (a) "At my school, I have a friend who really cares about me," (b) "At my school, I have a friend who talks with me about my problems," (c) "At my school, I have a friend who helps me when I'm having a hard time." The students were asked to indicate how much they agreed to these three statements on a 5-point Likert scale with 1 for strongly disagree and 5 for strongly agree. The average of scores from the three items was used to indicate the levels of support perceived by the students. High scores indicated perception of high peer support. The coefficient $\alpha$ of the three item-scores was .82. The test-retest reliability of this measure for the Hong Kong subsample $(n=100)$ was $.58(p<.001)$.

\subsubsection{Student engagement}

It is noted that many existing instruments have been developed to measure student engagement. However, the six-factor instrument of Appleton et al. (2006) includes facilitators of student engagement, whereas the four-factor instrument of Skinner et al. (2008) and the two-factor instrument of Finn et al. (1995) do not measure cognitive engagement. In addition, the three-factor instrument developed by Fredricks, Blumenfeld, Friedel, and Paris (2003) includes student outcome, such as discipline, in their measure. To be consistent with the three-part typology of student engagement described earlier, the present study adopted a newly developed scale that consists of three subscales, namely Affective Engagement, Behavioral Engagement, and Cognitive Engagement Subscales (Lam et al., 2009). The Affective Engagement Subscale consists of nine items that measure student's liking for learning and school (e.g., "I like what I am learning in school"). The Behavioral Engagement Subscale consists of 12 items that measure students' persistence and effort in learning (e.g., "I try hard to do well in school"). The Cognitive Engagement Subscale consists of 12 items that measure students' use of meaningful information processing strategies in learning (e.g., "When I study, I try to connect what I am learning with my own experiences"). The students were asked to indicate their agreement with the 33 items on a 5-point Likert scale with 1 for strongly disagree and 5 for strongly agree. The results of multiple-group confirmatory factor analysis (Lam et al., 2009) indicated that a three-factor model fit the data reasonably well and was invariant across the 12 countries. The three factors were highly correlated. The correlation coefficient was $.63(p<.001)$ for the association between Affective Engagement and Behavior Engagement, $.48(p<.001)$ for the association between Affective Engagement and Cognitive Engagement, and .54 $(p<.001)$ for the 
association between Behavioral Engagement and Cognitive Engagement. In view of the high correlation and the need for parsimony in analyses, the average of scores from the three subscales was used to indicate student engagement. High scores indicated high engagement. The coefficient $\alpha$ of the three subscale-scores was .78. The test-retest reliability of this measure for the Hong Kong subsample $(n=100)$ was .73 $(p<.001)$.

\subsubsection{Teachers' rating of academic performance}

The academic performance of the students was reported by their homeroom teachers. In countries where students did not have homeroom teachers, the teachers who had the most contact with the students were asked to make the report. As these teachers might teach different subjects, the academic performance they reported was not about specific subjects but about the subjects they themselves taught. They reported how much each of the students in their class was "good at school work," had "good performance on tests," and did "well on assignments." They were asked to indicate their agreement to the above three statements on a 5 -point Likert scale with 1 for strongly disagree and 5 for strongly agree. The average of scores from these three items was used as an indicator of the students' academic performance in school. High scores indicated good academic performance. The coefficient $\alpha$ of the three item-scores was .93, indicating a high internal consistency. Although the teachers who rated the students taught different subjects, the correlation between their ratings and the students' actual grade point average in the same academic year was .65 $(p<.001)$ for the Hong Kong subsample $(n=67)$.

\subsubsection{Gender}

The participants reported their gender at the end of the questionnaire. For the use in the regression analyses, girl was coded as 1 and boy as -1 .

\subsection{Procedures}

The participants were asked to complete the questionnaire in their schools. The questionnaire was either administered by their teachers or research assistants of the project. The questionnaire was in English for Austria, Canada, Malta, the United Kingdom, and the United States. It was in Chinese for China, Greek for Cyprus and Greece, Estonian for Estonia, Portuguese for Portugal, Korean for South Korea, and Romanian for Romania. Back-translation procedures (Brislin, 1970) were adopted to ensure conceptual equivalence across languages. The questionnaire was translated from English into the other languages and then translated back to English. The back-translated and original questionnaires were compared, and points of divergence were noted. The translation was then corrected to more accurately reflect the original questionnaire in English.

Because Institution Review Boards do not exist in all of the 12 countries, the practice of obtaining parental consent was not standardized. For instance, active parental consent was sought in Canada and the United States, whereas passive parental consent was sought in Austria, Estonia, Romania, and the United Kingdom. Other procedures for consent, such as seeking approval from local educational authorities and school principals, were used in China, Cyprus, Greece, Malta, Portugal, and South Korea. The consent rates for the active parental consent procedures in Canada and the United States were 64\% and 84\%, respectively. The consent rates for the passive parental consent procedure in Austria, Estonia, Romania, and the United Kingdom ranged from 97\% to 100\%. Data were collected between December 2007 and April 2009. The survey was administered at the end of a semester and the students were asked to answer the questions with reference to their experience in that semester. At about the same time, their teachers completed a rating form to report each student's academic performance in that semester.

\subsection{Data analyses}

The percentages of missing data for gender, teacher support, parent support, peer support, student engagement, academic performance, and gender were $0.8 \%, 2.3 \%, 0.5 \%, 0 \%, 6.9 \%$, and $0.4 \%$, respectively. Because the amount of missing data was not large, the results of subsequent analyses were unlikely to be biased (Bennett, 2001). To test whether missing data were at random, a dummy variable was created for each of these variables with two values: missing and not missing (Schlomer, Bauman, \& Card, 2010). The 
correlations of these dummy variables with other variables in the present study ranged from -.03 to .06 , indicating that whether the data were missing had little association with other variables. Given the small amount of missing data and the low correlation between the dummy variables and other variables, simple and traditional approaches were adopted to handle the missing data. Mean substitution was used to handle missing data for an item of a scale. Pairwise deletion was used when analyses involved two variables, but listwise deletion was used when analyses involved more than three variables. ${ }^{1}$

In the present study, the students were nested within 48 schools, 25 cities, and 12 countries. Therefore, it was necessary to ascertain whether multilevel analysis or single-level analysis was required. To do so, two analyses were conducted. In the first analysis, the intra-class correlation (ICC) of country was examined. The ICC was .06, indicating the proportion of total variance that occurred systematically between countries was trivial and multilevel analysis with country as Level-2 units was not necessary (Lee, 2000; Peugh, 2010). Second, the standard errors of the regression models conducted with and without multilevel analyses were compared. A three-level analysis with student as the first level, school as the second level, and city as the third level was conducted with student engagement regressed on gender, teacher support, parent support, and peer support. The standard errors of the coefficients for gender, teacher support, parent support, and peer support were .02, .01, .01, and .02, respectively. These standard errors were compared to those of the same model that was conducted with single-level analysis. It was found that they were almost the same. The standard errors of the coefficients for gender, teacher support, parent support, and peer support in the single-level analysis were $.02, .01, .01$, and .01 , respectively. Given the minimal differences found in the standard errors estimated assuming a single-level versus a multilevel model, a single-level model was used here ignoring the clustering of students within schools and cities.

To address the four objectives of the study, the following data analysis plan was used. First, to investigate whether girls and boys around the world have different levels of engagement in school and different perceptions of teacher, parent, and peer support, the effect size of the difference between the two genders on these variables was examined. Second, to investigate whether gender differences in school engagement account for the gender gap in academic achievement, a mediation analysis was conducted to examine the mediation effect of student engagement on the association between gender and academic performance. Third, to investigate gender differences in the relation between contextual supports, student engagement and academic performance, two sets of moderation analyses were performed. One examined gender as a moderator for the relation between contextual supports and student engagement. The other one examined gender as a moderator for the relation between contextual supports and academic performance. Fourth, to investigate whether teacher, parent, and peer support have similar or different indirect effects on student engagement for boys and girls, multiple-group structural equation modeling was performed to examine whether the partial mediation model proposed by Chen (2005) applied equally well to both genders. The answer for the first question can be hypothesized from the existing literature. It is reasonable to expect that girls have higher levels of engagement and perceptions of support than boys. However, the answers for the other three questions are not evident because of the inconclusive findings or lacunae in the literature. The results of the present study will thus contribute to the existing body of knowledge.

\section{Results}

\subsection{Gender differences in the five variables}

Table 2 presents the descriptive statistics of the five variables by gender. For each of the five variables, girls scored higher than boys. To examine whether the differences were significant, the results of $t$-tests were not considered because the sample size was so large that any trivial difference would be statistically significant. Instead, Cohen's $d$ was calculated and the effect size was examined. The Cohen's $d$ values for the gender differences in teacher support, parent support, peer support, student engagement, and academic performance were $.21, .15, .53, .23$, and .43 , respectively.

\footnotetext{
${ }^{1}$ It is noteworthy that deletion and single imputation approaches have many drawbacks. Recent methodological research has focused on two state-of-the-art missing data methods: maximum likelihood and multiple imputation. They provide unbiased estimates and are more apt to produce accurate parameter estimates (Baraldi \& Enders, 2010).
} 
Table 2

Means of and correlations between the variables for girls and boys.

\begin{tabular}{|c|c|c|c|c|c|c|c|c|}
\hline & Girls $(n=1725)$ & Boys $(n=1666)$ & Cohen's $d$ & 1 & 2 & 3 & 4 & 5 \\
\hline 1. Teacher support & $\begin{array}{l}3.89 \\
(0.87)\end{array}$ & $\begin{array}{l}3.70 \\
(0.98)\end{array}$ & 0.21 & - & $.33^{* *}$ & $.41^{* *}$ & $.48^{* *}$ & $.16^{* *}$ \\
\hline 2. Parent support & $\begin{array}{l}3.99 \\
(0.77)\end{array}$ & $\begin{array}{l}3.87 \\
(0.80)\end{array}$ & 0.15 & $.25^{* *}$ & - & $.28^{* *}$ & $.43^{* *}$ & $.14^{* *}$ \\
\hline 3. Peer support & $\begin{array}{l}4.35 \\
(0.83)\end{array}$ & $\begin{array}{l}3.88 \\
(0.95)\end{array}$ & 0.53 & $.36^{* *}$ & $.19^{* *}$ & - & $.30^{* *}$ & $.13^{* *}$ \\
\hline 4. Student engagement & $\begin{array}{l}3.44 \\
(0.56)\end{array}$ & $\begin{array}{l}3.31 \\
(0.56)\end{array}$ & 0.23 & $.48^{* *}$ & $.42^{* *}$ & $.22^{* *}$ & - & $.25^{* *}$ \\
\hline 5 Academic performance & $\begin{array}{l}3.85 \\
(0.96)\end{array}$ & $\begin{array}{l}3.42 \\
(1.04)\end{array}$ & 0.43 & $.16^{* *}$ & $.12^{* *}$ & .03 & $.22^{* *}$ & - \\
\hline
\end{tabular}

Note. Numbers in parentheses are standard deviations. Correlation coefficients below the diagonal are girls' and correlations coefficients above the diagonal are boys'. ${ }^{* *} p<.01$.

\subsection{Mediation effect of student engagement}

To test whether student engagement mediates the relation between gender and academic performance, a mediation analysis was conducted. According to Baron and Kenny (1986), there are three requirements for mediation. First, the independent variable (i.e., gender) significantly predicts the dependent variable (i.e., academic performance). Second, the independent variable (i.e., gender) significantly predicts the mediator variable (i.e., student engagement). Third, the mediator variable significantly predicts the dependent variable (i.e., academic performance) when analyses are adjusted for the independent variable. All these requirements were met. First, the total effect of gender on academic performance was significant $(\beta=.21, B=.21, p<.001)$. Girls tended to have better academic performance than boys. Second, as shown in Fig. 1 , gender significantly predicted student engagement $(\beta=.11, B=.06, p<.001)$. Girls tended to be more engaged in school than boys. Third, student engagement significantly predicted academic performance after controlling for gender $(\beta=.23, B=.45, p<.001)$. To examine the mediation effect, a Sobel test (Preacher \& Hayes, 2004) was conducted. The results showed that the mediation effect was significant, $z=5.8(p<.001)$. Taken as a whole, the results revealed that student engagement mediated the association between gender and academic performance. Girls tended to have higher engagement in school which in turn predicted their higher academic performance. However, it was noted that the mediation effect of student engagement was not complete because the direct effect of gender on academic performance was still significant $\left(E_{d}=.18, p<.001\right)$. In addition, the indirect effect of gender on academic performance through student engagement was not large, but it was significant statistically $\left(E_{i}=.03\right.$, $p<.001)$.

\subsection{Gender differences in the correlations}

Table 2 also presents the correlation coefficients between the five variables by gender. Many similarities were observed in the pattern of correlations between girls and boys. Perceived support from teachers,

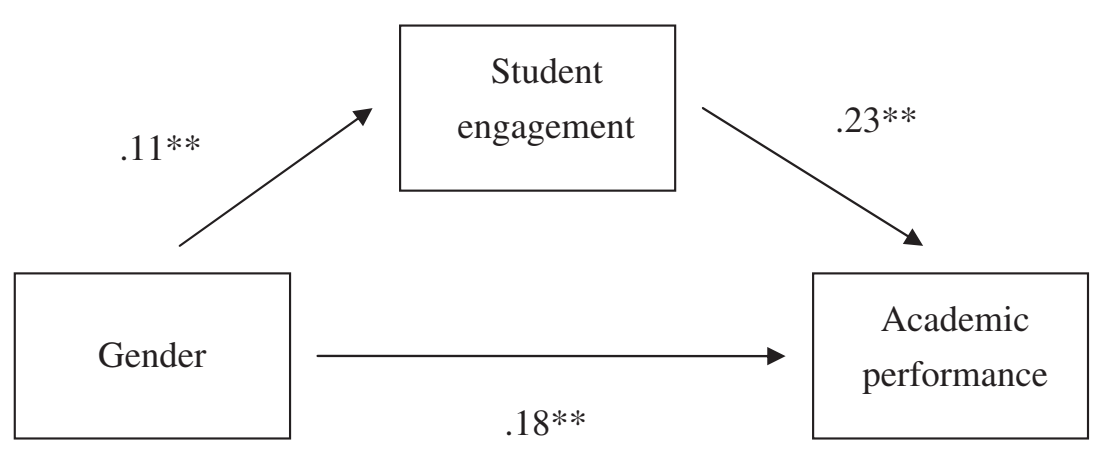

Fig. 1. The mediation effect of student engagement on the relation between gender and academic performance. ${ }^{* *} p<.01$. 
peers, and parents were associated significantly with student engagement. Among the three correlation coefficients, the one between perceived teacher support and student engagement was the highest. This pattern was the same for girls and boys $(r=.48, p<.001)$. In a similar vein, perceived support from teachers had the highest correlation with academic performance $(r=.16, p<.001)$. However, although perceived peer support was not significantly correlated with academic performance among girls $(r=.03, p=.29)$, it had a small correlation with academic performance among boys $(r=.13, p<.001)$.

To test whether gender moderates the predictability of student engagement and academic performance by the three perceived supports, two sets of hierarchical multiple regression analyses were completed. The dependent variables in the first and second sets of analyses were student engagement and academic performance, respectively. In the first set of analyses, student engagement was regressed on one of the three perceived supports and gender in Step 1, and then the interaction between that perceived support and gender. Three analyses instead of one analysis were conducted because the three-way and four-way interactions among the three perceived supports and gender were not the concern of the current study. In each of the three hierarchical multiple regression analyses, the interaction between one perceived support and gender was the focus. The results are presented in Table 3. In Step 1, the main effects of the three perceived supports and gender on student engagement were significant. The more the students perceived that their teachers, parents, and peers supported them, the more engaged they were in school. Because girl was coded as 1 and boy was coded as -1 , the positive $B$ coefficient of gender in each of the three analyses indicated that girls had better student engagement than boys. In Step 2, the interaction term between gender and the relevant support was added into the equation. The change of $R^{2}$ for Step 2 was not significant in any of the three analyses, indicating that gender did not significantly moderate the association between any of the three sources of support and student engagement. These results were more or less replicated in the second set of analyses with academic performance as the dependent variable.

Four hierarchical multiple regression analyses were conducted in the second set of analyses. Academic performance was regressed on gender, one of the three sources of support or student engagement in Step 1 and then the interaction term between gender and that support or student engagement in Step 2. The results of these four analyses are also presented in Table 3. The main effects of gender, the three sources of support, and student engagement were significant in Step 1. However, almost all of the interaction terms

Table 3

Hierarchical multiple regression analyses predicting student engagement and academic performance.

\begin{tabular}{|c|c|c|c|c|}
\hline \multirow[t]{2}{*}{ Predictors } & \multicolumn{2}{|c|}{ Student engagement } & \multicolumn{2}{|c|}{ Academic performance } \\
\hline & $\Delta R^{2}$ & $B$ & $\Delta R^{2}$ & $B$ \\
\hline Step 1 & $.24^{* *}$ & & $.07^{* *}$ & \\
\hline Teacher support & & $.48^{* *}$ & & $.16^{* *}$ \\
\hline Gender & & $.07^{* *}$ & & $.20^{* *}$ \\
\hline Step 2 & .00 & & .00 & \\
\hline Teacher support $\times$ Gender & & .02 & & .00 \\
\hline Step 1 & $.19^{* *}$ & & $.06^{* *}$ & \\
\hline Parent support & & $.42^{* *}$ & & $.13^{* *}$ \\
\hline Gender & & $.08^{* *}$ & & $.19^{* *}$ \\
\hline Step 2 & .00 & & .00 & \\
\hline Parent support $\times$ Gender & & .00 & & -.01 \\
\hline Step 1 & $.08^{* *}$ & & .05 & \\
\hline Peer support & & $.27^{* *}$ & & $.08^{* *}$ \\
\hline Gender & & $.05^{*}$ & & $.19^{* *}$ \\
\hline Step 2 & .00 & & .00 & \\
\hline Peer support $\times$ Gender & & -.02 & & $-.05^{* *}$ \\
\hline Step 1 & & & $.10^{* *}$ & \\
\hline Student engagement & & & & $.24^{* *}$ \\
\hline Gender & & & & $.18^{* *}$ \\
\hline Step 2 & & & .00 & \\
\hline Student engagement $\times$ Gender & & & & -.02 \\
\hline
\end{tabular}




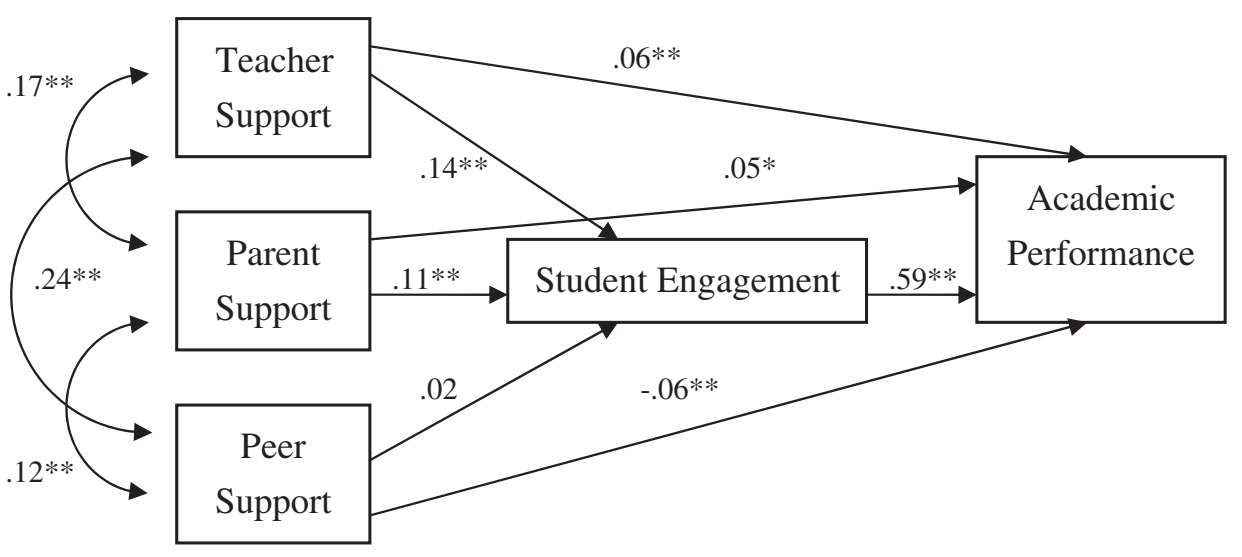

Fig. 2. The relation between teacher support, peer support, parent support, student engagement and academic performance. The coefficients are unstandardized coefficients under maximum likelihood. ${ }^{*} p<.05,{ }^{* *} p<.01$.

between gender and each of the three supports or student engagement were not statistically significant in Step 2. The only exception was the interaction term between peer support and gender. It is noteworthy that the $B$ coefficient was negative, indicating that the association between peer support and academic performance was weaker for girls but stronger for boys. As for the association between academic performance and the two other supports and student engagement, gender did not have a significant moderating effect. Thus, each association with academic performance did not depend on gender. The predictability of academic performance by teacher support, parent support, and student engagement did not differ for girls and boys.

\subsection{Testing the partial mediation model}

To test if the partial mediation model proposed by Chen (2005) fits equally well for girls and boys, LISREL 8.8 (Jöreskog \& Sörbom, 2007) was used to perform a multiple-group structural equation modeling analysis with the specifications that all the paths in Fig. 2 were equivalent across both gender groups. The results of this gender-equivalent model showed adequate goodness of fit, $\chi^{2}(9, N=3391)=99.44, p<.001$, $\mathrm{NNFI}=.92, \mathrm{CFI}=.96, \mathrm{SRMR}=.066$, and RMSEA $=.077$. The NNFI is the Non Normed Fit Index, and the CFI is the Comparative Fit Index, and each index should be at least larger than .90 to support reasonable goodness of fit ( $\mathrm{Hu} \&$ Bentler, 1998). In this gender-equivalent model, these fit statistics, NNFI $=.92$ and $\mathrm{CFI}=.96$, suggested that the data fit the proposed model very well. The SRMR is the standardized root mean square residual, and the RMSEA is the root mean squared error of approximation. Both the SRMR and RMSEA range in value from zero to one, with smaller values indicating better model fit. A value of .08 or less for the SRMR indicates adequate fit (Hu \& Bentler, 1998). An RMSEA value of less than .05 indicates close fit; RMSEA between .05 and .08 indicates reasonable fit, and RMSEA larger than .10 indicates inadequate fit (Browne \& Cudeck, 1993). For the results of this study, the CFI and NNFI index values supported good model fit. The RMSEA and SRMR values indicated that the proposed model fit the data fairly well. The results of this multiple-group, gender-equivalent model indicated that the partial mediation model would fit well for both girls and boys.

Fig. 2 also presents the unstandardized path coefficients in this gender-equivalent model. Among the three sources of support, perceived teacher support had the highest direct effect on student engagement $\left(E_{d}=.14, p<.001\right)$ and academic performance $\left(E_{d}=.06, p<.001\right)$. Perceived parent support ranked second. Its direct effects on student engagement $\left(E_{d}=.11, p<.001\right)$ and academic performance $\left(E_{d}=.05, p=.005\right)$ were both significant. By contrast, perceived peer support did not have any direct effect $\left(E_{d}=.02, p=.20\right)$ on student engagement and even had a negative direct effect on academic performance $\left(E_{d}=-.06\right.$, $p<.001$ ).

The LISREL output also provided the total and indirect effect estimates of the three sources of support on academic performance. These results are presented in Table 4. Among the three sources of support, perceived teacher support had the highest total effect on academic performance $\left(E_{t}=.14, p<.001\right)$. It also had the highest indirect effect on academic performance via student engagement $\left(E_{i}=.08, p<.001\right)$. 
Table 4

The total, direct, and indirect effect of the three supports on academic performance.

\begin{tabular}{lccc}
\hline Support & Total effect & Direct effect & Indirect effect \\
\hline Teacher support & $.14^{* *}$ & $.06^{* *}$ & $.08^{* *}$ \\
Parent support & $.11^{* *}$ & $.04^{*}$ & $.07^{* *}$ \\
Peer support & $-.05^{*}$ & $-.06^{* *}$ & .01 \\
\hline
\end{tabular}

Note.

** $p<.01$.

$* \quad p<.05$.

Perceived parent support had the second highest total effect $\left(E_{t}=.11, p<.001\right)$ and indirect effect $\left(E_{i}=.07\right.$, $p<.001$ ) on academic performance via student engagement. The total effect of perceived peer support on academic performance was negative $\left(E_{t}=-.05, p=.005\right)$. Its indirect effect on academic performance via student engagement was not significant $\left(E_{i}=.01, p=.20\right)$.

\section{Discussion}

Regarding the four objectives of the present study, the analyses revealed the following findings. First, compared to boys, girls reported higher engagement in school and obtained better academic performance according to their teachers' ratings. They also perceived higher support from teachers, parents, and peers. The effect sizes were not trivial (Urdan, 2001), especially for academic performance and perceived peer support. Second, student engagement was a mediator in the association between gender and academic performance. It accounted for the gender differences in academic performance although the mediation effect was not large. Third, gender did not moderate the association between student engagement and academic performance. Furthermore, gender did not moderate the association between the three contextual supports and student engagement. The predictability of student engagement by the three contextual supports was the same across the two genders. In addition, gender did not moderate the predictability of academic performance by teacher and parent supports. How these two sources of support related to academic performance did not vary across the two genders. The only moderation effect of gender was found in peer support. The association between peer support and academic performance was stronger for males. Finally, the partial mediation model proposed by Chen (2005) fit well for both girls and boys. Perceived teacher support had the highest total, direct, and indirect effects on academic performance. Perceived parent support ranked the second and perceived peer support ranked the last.

\subsection{Findings relative to previous studies}

Some of the findings from the present study are consistent with those of previous studies, whereas others are not. Data from the 12 countries in this project indicate that teachers perceived girls to have better academic performance than boys. This finding is consistent with the findings of many previous studies (e.g., Epstein et al., 1998; Mau \& Lynn, 2001). The present study also found that student engagement, as a personality and motivation factor, could account for some of the gender differences in academic performance. Although no previous studies have investigated the role of student engagement in the achievement gender gap, herein, the finding that student engagement mediated the association between gender and academic performance is in line with those of previous studies that investigated the role of personality and motivation factors in gender differences in school achievement. For instance, Hicks et al. (2008) found that achievement striving, self-control, and aggression accounted for gender differences in grade point average (GPA). Each of these personality traits was a significant predictor of GPA, with sex differences in aggression accounting for one-half of the gender differences in GPA. The finding of the present study about the mediation effect of student engagement provides additional empirical support to the claim of many researchers that gender differences in school performance lie in personality and motivation factors instead of cognitive factors (e.g., Freudenthaler et al., 2008; Hicks et al., 2008; Johnson, 2008; Ruban \& McCoach, 2005). However, it is noteworthy that the mediation effect of student engagement on the association between gender and academic performance was small in the present study 
with a large sample size. This finding implies that many more personality and motivation factors may be accounting for the gender differences in academic performance. It is important for researchers to continue with the search for such factors.

In the present study, student engagement was associated with academic performance, and the three contextual supports. It is noteworthy that these associations did not vary across the two genders. Gender did not have any moderation effect. These findings are different from those of Freudenthaler et al. (2008), who found that school-related intrinsic motivation was more important to school achievement for boys than for girls. However, the findings from the present study are consistent with those of Ruban and McCoach (2005); Sánchez, Colón, and Esparza (2005); and Steinmayr and Spinath (2008). They did not find differences in the predictability of school performance and the relative importance of predictors across the two genders.

This study also supported student engagement as a partial mediator for the association between support from teachers, parents, and peers and academic performance. The findings are consistent with those from Chen (2005). In addition, the results of multiple-group analysis indicate that this partial mediation model is invariant across gender. Although girls scored higher than boys in every variable in the present study, how these variables related to one another was similar across the two genders. Girls and boys were not different in how their engagement and academic performance were predicted by their perceptions of teacher, parent and peer support.

The present study examined all the three sources of supports (i.e., teacher, parent, and peer). Thus, it was possible to explore the relative importance of these sources of support to student engagement and academic achievement. It was found that teacher support had the highest total, direct, and indirect effects on academic performance. Parent support ranked the second and peer support ranked the last. These findings are almost identical with those of Chen (2005), who found that teacher, parent, and peer supports were all related indirectly to academic achievement mediated by academic engagement. The strength of the associations, however, varied by support system, with teacher support to academic achievement being the strongest, followed by parent support, and then peer support. Both the present study and Chen (2005) showed that peer support was not as important as teacher and parent supports in predicting student engagement. This finding appears counterintuitive and does not seem to be consistent with the common belief that peers are influential to adolescents. Nevertheless, this seeming inconsistency is understandable when the support from teachers, parents, and peers are compared across various outcomes of children. In a study with 6th-grade students, Wentzel (1998) found that peer support was a positive predictor of prosocial goal pursuit; teacher support was a positive predictor of class-related and school-related interest, and parent support was a positive predictor of school-related interest and goal orientations. Different outcomes were associated with support from different socializing agents. Peer support was still important, although it was not as important as teacher and parent support when the matter of concern was schoolrelated interest. The findings of Wentzel (1998) were consistent with those of the present study.

\subsection{Implications for the work of school psychologists}

The present study has enhanced the existing body of knowledge about the contextual and personal factors associated with girls' and boys' academic performance around the world. These findings have important implications for educational practices. Overall, boys are likely to be less engaged than girls in school. This gender difference can account at least partially for the gender gap in academic performance. Thus, helping to enhance student engagement at school is likely to result in better academic performance. However, how to enhance student engagement is an important question. The results of the present study shed light in this respect. The findings provide support to Furlong and Christenson (2008) that student engagement "is highly influenced by contextual factors - home, school, and peers" (p. 366). Indeed, the key to enhance boys' engagement in school may lie in the enhancement of support from teachers, parents, and peers.

The results of the present study suggest that students' perception of teacher support is the strongest predictor of their engagement in school. Its association with student engagement and academic performance is even higher than that of parents and much more than that of peers. This pattern implies that teachers have a very important role to play in enhancing student engagement in school. When students perceive care and concern from their teachers, the chances for them to be engaged in school are 
higher. School psychologists may be important catalysts in the promotion of teacher support of students because they can help increase teacher support directly and indirectly. For example, in recent years, school psychologists have been involved actively in the establishment of positive behavior support at the schoolwide level (Horner, Crone, \& Stiller, 2001). The use of positive behavior support decreases the need for more intrusive or aversive intervention (i.e., punishment or suspension) that is harmful to teacher-student relationship. Because boys tend to display more behavior problems than girls in school, positive behavior support will be particularly beneficial to boys (Hughes, Cavell, \& Willson, 2001; O'Connor, Dearing, \& Collins, 2011). It can help them maintain better relationships with their teachers and feel more supported by their teachers.

In addition to promoting teacher support, school psychologists can also play an important role in promoting parent and peer support. To promote parent support, they can advocate for increased homeschool collaboration and identify strategies to encourage parental participation (National Association of School Psychologists, 2005). For example, they can serve as a liaison to support communication among homes and schools. School psychologists can also provide direct service to families regarding strategies that promote academic, behavioral, and social success across environments. To increase peer support in school, they can help build a safe and positive learning environment for all students. For example, they can provide direct service to the students with behavioral, social, or emotional problems and to all students regarding the prevention of school bullying (Olweus, 1997). Student engagement is malleable because its contextual factors are also malleable, and thus school psychologists can help shape these malleable contextual factors.

\subsection{Limitations and directions for future research}

Despite its contributions to the existing body of knowledge about student engagement, the present study has some obvious limitations. First, the cross-sectional and correlational data of this study leave the causal status among variables ambiguous. Although the terms "direct effects" and "indirect effects" are used according to the statistical conventions in mediation analyses, they do not imply any causality. To determine the directionality of causality, future studies may consider longitudinal designs that allow time series analyses. Second, the procedures for parental consent were not standardized across the 12 countries because they had different infrastructures and requirements regarding the regulation of research activities. It is acknowledged that these differences might have caused sample bias. The countries that adopted active parental consent might have excluded the students who were less engaged. There is a possibility that the students who volunteered to participate and sent in parental consent forms were those who were more engaged in school. In future studies that involve data from multiple countries, researchers need to pay attention to the parental consent procedures that may cause sample bias. Passive parental consent may be a promising solution to this problem. In the present study, the countries that adopted a passive parental consent procedure obtained consent rates close to $100 \%$. This procedure is more inclusive and less likely to exclude the students who are less engaged in school.

Another limitation of the present study lies in its reliance on self-report measures from students. There is a possibility of inflation of correlations when variables are measured at the same time from the same participants. Although self-reports are valid measures of subjective psychological constructs, such as perceived support from teachers, parents, and peers, the results of the present study would be much stronger if measures other than self-reports were included to represent these constructs. For example, inputs from teachers, parents, and peers may be used to corroborate student perception. In addition, academic performance in the present study was measured by teacher ratings. Although previous research has indicated that teacher ratings usually have a high correlation with standardized test scores (Gruman, Harachi, Abbott, Catalano, \& Fleming, 2008), they are still susceptible to some confounding factors. For example, teachers may rate girls higher than boys on academic performance for conscientious behaviors such as following directions, conforming to expectations, or taking care of being neat (De Fruyt, Van Leeuwen, De Bolle, \& De Clercq, 2008; Freudenthaler et al., 2008). As a result, teacher ratings may be a biased measure of academic performance. In addition, the teachers in the present study taught different subjects and their ratings might not be comparable. To avoid these problems, future studies may consider using GPA or objective achievement tests of the same subjects. 
To capture the three dimensions of student engagement, the present study adopted a newly developed instrument (Lam et al., 2009). Although the results of confirmatory factor analysis, internal consistency analysis, and test-retest reliability analysis indicated that the instrument had adequate psychometric properties, there is still a need for further psychometric support. As Cronbach and Meehl (1995) pointed out, validation of an instrument is a complex and continual process that requires the integration of evidence from many different sources. One possible direction for future work is to examine the correlations of this instrument with other existing measures for convergent and divergent validity.

Given that gender differences were the focus of this investigation, cultural differences were not explored in the present study. Nevertheless, it is still worthwhile for future studies to look into how culture may play a role in the gender differences in student engagement and academic performance. In addition, another possible direction for future studies is to look into school effects. In the present study, students were nested within 48 schools from 25 cities in 12 countries. Schools might have an effect on how students were engaged in school. Past studies have suggested that school's ecology is associated with students' sense of school connectedness (Anderman, 2002; Waters, Cross, \& Shaw, 2010). It is worthwhile to investigate what structural, functional, and built aspects of school are essential to student engagement. However, the present study did not have such information for a meaningful multilevel analysis on school effects.

\subsection{Conclusions}

In sum, the present study has provided insights into many interesting questions about gender differences in academic achievement. Yet, it has also led researchers and educators to many more perplexing questions. The results of the present study indicate clearly the pivotal role of teacher and parent support in student engagement and academic performance. However, why did boys perceive less teacher and parent support than girls? What may have contributed to such a gender difference in the perception of support from these important agents of socialization? In addition, the present study has shown that student engagement partially mediated the association between gender and academic performance. However, the mediation effect was small, and most of the variance in academic performance has not been accounted for. The association between gender and academic performance is likely to be mediated by many other personality and motivation factors. What are these factors and how do they contribute to the gender gap in education? These unanswered questions require further investigation by researchers in future studies.

\section{References}

Ablard, K. E., \& Lipschultz, R. E. (1998). Self-regulated learning in high-achieving students: Relations to advanced reasoning achievement goals, and sex. Journal of Educational Psychology, 90, 94-101.

Anderman, E. M. (2002). School effects on psychological outcomes during adolescence.Journal of Educational Psychology, 94, 795-809.

Appleton, J. J., Christenson, S. L., Kim, D., \& Reschly, A. L. (2006). Meauring cognitive and psycholgoical engagement: Validation of the student engagement instrument. Journal of School Psychology, 44, 427-445.

Archambault, I., Janosz, M., Fallu, J. -S., \& Pagani, L. S. (2009). Student engagement and its relationship with early high school dropout. Journal of Adolescence, 32, 651-670.

Baraldi, A. N., \& Enders, C. K. (2010). An introduction to modern missing data analyses. Journal of School Psychology, 48, 5-37.

Barber, M. (1996). The learning game: Arguments for an education revolution. London: Victor Gollancz.

Baron, R. M., \& Kenny, D. A. (1986). The moderator-mediator variable distinction in social psychological research: Conceptual, strategic, and statistical considerations. Journal of Personality and Social Psychology, 51, 1173-1182.

Bennett, D. A. (2001). How can I deal with missing data? Australia and New Zealand Journal of Public Health, 25, 464-469.

Birch, S. H., \& Ladd, G. W. (1997). The teacher-child relationship and children's early school adjustment. Journal of School Psychology, 35, 61-79.

Brislin, R. W. (1970). Back-translation for cross-cultural research. Journal of Cross Cultural Psychology, 1, 185-216.

Bronfenbrenner, U. (1977). Toward an experimental ecology of human development. American Psychologist, 513-531.

Browne, M. W., \& Cudeck, R. (1993). Alternative ways of assessing model fit. In K. A. Bollen, \& J. S. (Eds.), Testing structural equation models (pp. 136-162). Newbury Park, CA: Sage.

Ceci, S. J., Williams, W. M., \& Barnett, S. M. (2009). Women's underrepresentation in science: Sociocultural and biological considerations. Psychological Bulletin, 135, 218-261.

Chen, J. J. -L. (2005). Relation of academic support from parents, teachers, and peers to Hong Kong adolescents' academic achievement: The mediating role of academic engagement. Genetic, Social, and General Psychology Monographs, 131, 77-127.

Connell, J. P., Spencer, M. B., \& Aber, J. L. (1994). Educational risk and resilience in African-American youth: Context, self, action, and outcomes in school. Child Development. Special Issue: Children and Poverty, 65, 493-506. 
Connell, M. P., \& Wellborn, J. G. (1991). Competence, autonomy and relatedness: A motivational analysis of self-system processes. In M. R. Gunnar, \& L. A. Sroufe (Eds.), Self processes and development: The Minnesota Symposia on Child Development, Vol. 23. (pp. 43-78)Hillsdale, NJ: Erlbaum.

Cowie, H., \& Fernández, F. J. (2006). Peer support in school: Implementation and challenges. Electronic Journal of Research in Educational Psychology, 4, 291-310 Retrieved from http://www.investigacion-psicopedagogica.org/revista/new/english/ LeerArticulo.php

Cox, T. (2000). Pupils' perspectives on their education. In T. Cox (Ed.), Combating educational disadvantage. Meeting the needs of vulnerable children. London: Falmer Press.

Cronbach, L. J., \& Meehl, P. E. (1995). Construct validity in psychological tests. Psychological Bulletin, 52, 281-302.

Darom, E., \& Rich, Y. (1988). Sex-differences in attitudes toward school: Student self-reports and teacher perceptions. British Journal of Educational Psychology, 58, 350-355.

De Fruyt, F., Van Leeuwen, K., De Bolle, M., \& De Clercq, B. (2008). Sex differences in school performance as a function of conscientiousness, imagination and the mediating role of problem behaviour. European Journal of Personality, 22, 167-184.

DiPerna, J. C., Volpe, R. J., \& Elliott, S. N. (2005). A model of academic enablers and mathematics achievement in the elementary grades. Journal of School Psychology, 43, 379-392.

Eccles, J. S., Midgley, C., Wigfield, A., Buchanan, C. M., Reuman, D., Flanagan, C., et al. (1993). Development during adolescence: The impact of stage-environment fit on young adolescents' experiences in schools and in families. American Psychologist, 48, 90-101.

Epstein, D., Elwood, J., Jey, V., \& Maw, J. (1998). Failing boys? Issues in gender and achievement. Buckingham, PA: Open University Press.

Finn, J. D. (1989). Withdrawing from school. Review of Educational Research, 59, 117-142.

Finn, J. D., Pannozzo, G. M., \& Voelkl, K. E. (1995). Disruptive and inattentive withdrawn behavior and achievement among fourth graders. The Elementary School Journal, 95, 421-454.

Fredricks, J. A., Blumenfeld, P. C., Friedel, J., \& Paris, A. H. (2003, March). School engagement. Paper presented at the Indicators of Positive Development Conference, Washington, D.C.

Fredricks, J. A., Blumenfeld, P. C., \& Paris, A. H. (2004). School engagement: Potential of the concept, state of the evidence. Review of Educational Research, 74, 59-109.

Freudenthaler, H. H., Spinath, B., \& Neubauer, A. C. (2008). Predicting school achievement in boys and girls. European Journal of Personality, 22, 231-245.

Furlong, M. J., \& Christenson, S. L. (2008). Engaging students at school and with learning: A relevant construct for ALL students. Psychology in the Schools, 45, 365-368.

Furrer, C., \& Skinner, E. (2003). Sense of relatedness as a factor in children's academic engagement and performance. Journal of Educational Psychology, 95, 148-162.

Gest, S. D., Welsh, J. A., \& Domitrovich, C. E. (2005). Behavioral predictors of changes in social relatedness and liking school in elementary school. Journal of School Psychology, 43, 281-301.

Gruman, D. H., Harachi, T. W., Abbott, R. D., Catalano, R. F., \& Fleming, C. B. (2008). Longitudinal effects of student mobility on three dimensions of elementary school engagement. Child Development, 79, 1833-1852.

Harris, J. (1998). The nurture assumption: Why children turn out the way they do. New York: Free Press.

Hatzichristou, C., \& Hopf, D. (1996). A multiperspective comparison of peer sociometric status groups in childhood and adolescence. Child Development, 67, 1085-1102.

Hicks, B. M., Johnson, W., Iacono, W. G., \& McGue, M. (2008). Moderating effects of personality on the genetic and environmental influences of school grades helps to explain sex differences in scholastic achievement. European Journal of Personality, 22, 247-268.

Hofstede, G. (2009). Geert Hosfstede ${ }^{\mathrm{TM}}$ Cultural Dimensions. Retrieved from http://www.geert-hofstede.com/hofstede_dimensions.php

Hoover-Dempsey, K. V., \& Sandler, H. M. (1995). Parental involvement in children's education: Why does it make a difference? Teacher College Record, 97, 310-331.

Horner, R. H., Crone, D. A., \& Stiller, B. (2001, March). The role of school psychologists in establishing positive behavior support: Collaborating in systems change at the school-wide level. Communiqué, 29, 10-12.

Hu, L., \& Bentler, P. M. (1998). Fit indices in covariance structure modeling: Sensitivity to underparameterized model misspecification. Psychological Methods, 3, 424-453.

Hughes, J. N., Cavell, T. A., \& Willson, V. (2001). Further support for the developmental significance of the quality of the teacherstudent relationship. Journal of School Psychology, 39, 289-301.

Jimerson, S., Campos, E., \& Greif, J. (2003). Towards an understanding of definitions and measures of student engagement in schools and related terms. The California School Psychologist, 8, 7-28.

Johnson, W. (2008). Beyond conscientiousness: A personality perspective on the widening sex difference in school performance. European Journal of Personality, 22, 163-166.

Jöreskog, K. G., \& Sörbom, D. (2007). LISREL 8.8: User's reference guide. Chicago: Scientific Software.

Kenney-Benson, G. A., Pomerantz, E. M., Ryan, A. M., \& Patrick, H. (2006). Sex differences in math performance: The role of children's approach to schoolwork. Developmental Psychology, 42, 11-26.

Ladd, G. W., Kochenderfer, B. J., \& Coleman, C. C. (1997). Classroom peer acceptance, friendship, and victimization: Distinct relational systems that contribute uniquely to children's school adjustment? Child Development, 68, 1181-1197.

Lam, S.-f., Jimerson, S., Basnett, J., Cefai, C., Duck, R., Farrell, P., et al. (2009, July). Exploring student engagement in schools internationally: A collaborative international study yields further insights. A symposium at the 31st Annual International School Psychology Association Colloquium, Malta.

Lee, V. (2000). Using hierarchical linear modeling to study social contexts: The case of school effects. Educational Psychologist, 35, 125-141.

Mau, W., \& Lynn, R. (2001). Gender differences on the Scholastic Aptitude Test, the American College Test, and college grades. Educational Psychology, 21, 133-136.

Murray, C., \& Greenberg, M. T. (2001). Relationships with teachers and bonds with school: Social emotional adjustment correlates for children with and without disabilities. Psychology in the Schools, 38, 25-41.

National Association of School Psychologists (2005). Home-school collaboration (position statement). Bethesda, MD: Author.

O'Connor, E. E., Dearing, E., \& Collins, B. A. (2011). Teacher-child relationship and behavior problem trajectories in elementary school. American Educational Research Journal, 48, 120-162.

Olweus, D. (1997). Bully/victim problems in school: Facts and intervention. European Journal of Psychology of Education, 12, 495-510. 
Patrick, H., Ryan, A. M., \& Pintrich, P. R. (1999). The differential impact of extrinsic and mastery goal orientations on males' and females' self-regulated learning. Learning and Individual Differences, 11, 153-171.

Perkins, R., Kleiner, B., Roey, S., \& Brown, J. (2004). The High School Transcript Study: A decade of change in curriculum and achievement, 1990-2000 (Report No. NCES 2004455). Washington, DC: U.S. Department of Education, National Center for Education Statistics.

Peugh, J. L. (2010). A practical guide to multilevel modeling. Journal of School Psychology, 48, 85-112.

Pomerantz, E. M., Alterman, E. R., \& Saxon, J. L. (2002). Making the grade but feeling distressed: Gender differences in academic performance and internal distress. Journal of Educational Psychology, 94, 396-404.

Preacher, K. J., \& Hayes, A. F. (2004). SPSS and SAS procedures for estimating indirect effects in simple mediation models. Behavior Research Methods, Instruments, E' Computers, 36, 717-731.

Rosenfeld, L. B., Richman, J. M., \& Bowen, G. L. (2000). Social support networks and school outcomes. Child and Adolescent Social Work Journal, 17, 205-226.

Ruban, L., \& McCoach, D. B. (2005). Gender differences in explaining grades using structural equation modelling. The Review of Higher Education, 28, 475-502.

Ryan, R. M., \& Deci, E. L. (2000). Self-determination theory and the facilitation of intrinsic motivation, social development, and wellbeing. American Psychologist, 55, 68-78.

Sánchez, B., Colón, Y., \& Esparza, P. (2005). The role of sense of school belonging and gender in the academic adjustment of Latino adolescents. Journal of Youth and Adolescence, 34, 619-628.

Schlomer, G. L., Bauman, S., \& Card, N. A. (2010). Best practices for missing data management in counseling psychology. Journal of Counseling Psychology, 57, 1-10.

Sinclair, M. F., Christenson, S. L., Lehr, C. A., \& Anderson, A. R. (2003). Facilitating school engagement: Lessons learned from Check \& Connect longitudinal studies. California School Psychologists, 8, 29-41.

Skinner, E. A., \& Belmont, M. J. (1993). Motivation in the classroom: Reciprocal effects of teacher behavior and student engagement across the school year. Journal of Educational Psychology, 85, 571-581.

Skinner, E., Furrer, C., Marchand, G., \& Kindermann, T. (2008). Engagement and disaffection in the classroom: Part of a larger motivational dynamic? Journal of Educational Psychology, 100, 765-781.

Steinberg, L., Lamborn, S. D., Dornbusch, S. M., \& Darling, N. (1992). Impact of parenting practices on adolescent achievement: Authoritative parenting, school involvement, and encouragement to succeed. Child Development, 63, 1266-1281.

Steinmayr, R., \& Spinath, B. (2008). Sex differences in school achievement: What are the roles of personality and achievement motivation? European Journal of Personality, 22, 185-209.

Urdan, T. (2001). Statistics in plain English. London: Lawrence Erlbaum.

Van Houtte, M. (2004). Why boys achieve less at school than girls: The difference between boys' and girls' academic culture. Educational Studies, 30, 159-173.

Voelkl, K. E. (1997). Identification with school. American Journal of Education, 105, 204-319.

Waanders, C., Mendez, J., \& Downer, J. (2007). Parent characteristics, economic stress and neighborhood context as predictors of parent involvement in preschool children's education. Journal of School Psychology, 45, 619-636.

Walberg, H. J. (1981). A psychological theory of educational productivity. In F. H. Farley, \& N. Gordon (Eds.), Psychology and education (pp. 81-110). : Chicago7 National Society for the Study of Education.

Walker, C. O., Greene, B. A., \& Mansell, R. A. (2006). Identification with academics, intrinsic/extrinsic motivation, and self-efficacy as predictors of cognitive engagement. Learning and Individual Differences, 16, 1-12.

Warrington, M., Younger, M., \& Williams, J. (2000). Student attitudes, image and the gender gap. British Educational Research Journal, 26, 374-381.

Waters, S., Cross, D., \& Shaw, T. (2010). Does the nature of schools matter? An exploration of selected school ecology factors on adolescent perceptions of school connectedness. British Journal of Educational Psychology, 80, 381-402.

Wentzel, K. R. (1998). Social relationships and motivation in middle school: The role of parents, teachers and peers. Journal of Educational Psychology, 90, 202-209.

WestEd (2000). California Healthy Kids Survey. Los Alamitos, CA: WestEd.

Willingham, W., \& Cole, N. (1997). Gender and fair assessment. Mahwah, NJ: Erlbaum.

Wong, K. -C., Lam, Y. R., \& Ho, L. -M. (2002). The effects of schooling on gender differences. British Educational Research Journal, 28, $827-843$.

Wu, J. -Y., Hughes, J. N., \& Kwok, O. -M. (2010). Teacher-student relationship quality type in elementary grades: Effects on trajectories for achievement and engagement. Journal of School Psychology, 48, 357-387.

Ysseldyke, J., \& Christenson, S. (2002). Functional assessment of academic behavior: Creating successful learning environments. Longmont, CO: Sopris West.

Zimmerman, B. J., \& Martinez-Pons, M. (1990). Student differences in self-regulated learning: Relating grade, sex, and giftedness to self-efficacy and strategy use. Journal of Educational Psychology, 82, 51-59. 